\title{
Broiler chicken body weights, feed intakes, plasma lipid and small-intestinal bile acid concentrations in response to feeding of chitosan and pectin
}

\author{
BY A. RAZDAN, D. PETTERSSON AND J. PETTERSSON \\ Department of Food Science, Swedish University of Agricultural Sciences, S-750 07 Uppsala, Sweden
}

(Received 13 November 1995-Revised 4 December 1996-Accepted 2 January 1997)

\begin{abstract}
One-day-old broiler chickens were fed on a control diet based on maize and maize starch or diets containing $30 \mathrm{~g} / \mathrm{kg}$ of $89 \%$ deacetylated chitin (chitosan) or low-methoxyl (34\% degree of esterification) pectin. Feeding of the chitosan diet to chickens significantly reduced body weights and feed intakes compared with animals fed on control or pectin diets on days 5 and 11 of the experiment. On day 12, significant reductions in total plasma cholesterol and HDL-cholesterol concentrations were observed among birds fed on the chitosan but not the pectin diet in relation to control-fed animals. A concomitant increase in the plasma HDL-cholesterol:total cholesterol ratio was observed among chitosan-fed chickens. The generally reduced concentrations of primary and total bile acids in the duodenum of birds fed on the fibre-containing diets on day 13 may have been an indication of a delay in the production and/or secretion of bile. Viscosity of the three broilerchicken diets was measured after suspension in water, acidification and finally neutralization of the suspensions, in an attempt to simulate the effect of changes in $\mathrm{pH}$ and dilution of diets occurring in the gizzard and small intestine of chickens. Viscosity of the chitosan diet was significantly elevated after acidification and significantly reduced at neutralization in comparison with the control and pectin-containing diets suggesting that the hypolipidaemic influence of chitosan observed in the present study may be due to interruption of enterohepatic bile acid circulation rather than increased viscosity in the small intestine of chickens. The low viscosity of the pectin diet in vitro together with the absence of a hypocholesterolaemic effect of this diet when fed in vivo precludes any conclusion regarding the hypocholesterolaemic mechanism of pectin observed in earlier studies.
\end{abstract}

Chitosan: Pectin: Plasma: Bile acids: Viscosity

The suggestion by Trowell (1972) that dietary fibre might reduce plasma lipid concentrations has stimulated a great deal of research concerning the hypolipidaemic effects of soluble dietary fibres from different sources in both animals and human subjects (Chang \& Johnson, 1985; Welch et al. 1986; Anderson, 1987; Ikeda et al. 1993). Although the beneficial health effects of dietary fibres are now well established and many mechanisms for their hypocholesterolaemic action have been proposed, it would seem that no dominant mechanism has been established which can fully explain the lipid-reducing responses reported (Furda, 1990). The suggestion that increased intestinal viscosity, resulting from increased fibre consumption, may inhibit uptake of dietary fat is confounded by the difficulty in measuring intestinal viscosity although some evidence of increased intestinal viscosity resulting from feeding of viscous dietary fibres is available (Ikegami et al. 1990; Cameron-Smith et al. 1994). Another proposal is that dietary fibres bind to bile acids which are subsequently excreted leading to an imbalance in enterohepatic cholesterol circulation. Losses in bile acids promote replenishment of the bile acid pool by synthesis from cholesterol in the liver which would entail reductions in plasma cholesterol levels. 
The degree of bile acid excretion varies depending on the type of dietary fibre consumed (Kishimoto et al. 1995). Several recently published reports have indicated that increased excretion of bile acids (Maezaki et al. 1993) and dietary fat (Deuchi et al. 1994; Kanauchi et al. 1994) does occur in response to consumption of the dietary fibre chitosan. Binding of bile acids or mixed micelles by cationic chitosan may be a cause of the observed increases in faecal sterols. Pectins on the other hand are polyanions and although increases in faecal sterol excretion in rats fed on pectin diets have been observed, the mechanism by which this is achieved is probably not the same as for chitosan.

Since the mechanisms by which pectin and chitosan exert their hypocholesterolaemic actions are probably different it follows that the bile salt and plasma lipid levels would be expected to be affected to different extents. The purpose of the present experiment was, therefore, to establish the in vivo effects of ad libitum feeding of a control diet supplemented with an $89 \%$ deacetylated chitin (chitosan) or low-methoxyl pectin on broiler chicken body weights and feed intakes, plasma lipids and duodenal bile acid composition and concentration. If different effects of pectin and chitosan on these variables were to be observed they may be explained by the relative solubilities of the two polysaccharides in the gastrointestinal tract. In order to establish the influence of changes in solubility and $\mathrm{pH}$ as well as dilution of the polysaccharides by secretions expected in the gastrointestinal tracts of chickens, an in vitro experiment using the control, pectin and chitosan diets used in the in vivo part of the study was also performed.

\section{MATERIALS AND METHODS}

\section{Chitosan and pectin fractions}

An $89 \%$ deacetylated chitin (chitosan) fraction with a viscosity of $510 \mathrm{mPa} . \mathrm{s}$ was supplied by Pronova Biopolymer, Drammen, Norway. The pectin used was a low-methoxyl pectin ( $34 \%$ degree of methyl esterification) supplied by Grindsted Products, Brabrand, Denmark.

\section{Diets}

The chickens received a control diet based on maize $(600.6 \mathrm{~g} / \mathrm{kg}$ feed) and maize starch $(168.5 \mathrm{~g} / \mathrm{kg}$ feed) or isoenergetic diets in which part $(30 \mathrm{~g} / \mathrm{kg})$ of the maize-starch component was replaced by chitosan or pectin fractions (Table 1). Lysine and methionine were included at levels of 4.0 and $1.9 \mathrm{~g} / \mathrm{kg}$ respectively in each of the mash diets, which were milled to pass a $3.5 \mathrm{~mm}$ screen.

\section{Chickens}

A total of ninety-six 1-d-old broiler chickens (Ross) of mixed sex were randomly divided into twelve groups of eight chickens with an average group weight of $409 \mathrm{~g}$ and a maximum difference in weight of $4 \mathrm{~g}$ between groups. The groups were randomly allocated to battery cages with raised wire floors. The cages were arranged in a stack system consisting of four cages per stack, and four stacks of cages (only twelve cages in total) were used in this experiment. Cages were placed in a windowless, light- and temperaturecontrolled room. The three experimental diets were randomly assigned to four replicates (cages) each with each cage containing eight animals. Chickens were wing-banded and their sex determined on day 1 of the experiment. All diets were given ad libitum and the birds had free access to feed except for $8 \mathrm{~h}$ before blood collection for analysis of plasma 
Table 1. Composition of the control, chitosan and pectin diets ( $\mathrm{g} / \mathrm{kg}$ air-dry basis)

\begin{tabular}{lccc}
\hline & \multicolumn{3}{c}{ Diets } \\
\cline { 2 - 4 } & Control & Chitosan & Pectin \\
\hline Maize & 600.6 & 600.6 & 600.6 \\
Fish meal & 101.5 & 101.5 & 101.5 \\
Meat-and-bone meal & 90.4 & 90.4 & 90.4 \\
Animal fat & 20.0 & 20.0 & 20.0 \\
Maize starch & 168.5 & 138.5 & 138.5 \\
Chitosan & - & 30.0 & -10 \\
Pectin & - & - & 30.0 \\
Mono-calcium phosphate & 2.1 & 2.1 & 2.1 \\
Vitamin and trace element premix* & 10.0 & 10.0 & 10.0 \\
Salt (NaHCO ${ }_{3}$ ) & 1.0 & 1.0 & 1.0 \\
Lysine (HCl) & 4.0 & 4.0 & 4.0 \\
DL-Methionine & 1.9 & 1.9 & 1.9 \\
\hline \hline
\end{tabular}

* For details of composition see Pettersson \& Åman (1992).

lipids on day 12. Chickens had free access to water for the duration of the experiment. The conditions and standards of care employed in this study were approved by the Ethical Committee for Animal Experiments in Uppsala, Sweden.

\section{Production study}

Individual chicken weights and group cumulative feed intakes were recorded at 5 and $11 \mathrm{~d}$ of age and group feed conversion ratios were calculated on a weight-gain basis.

\section{Viscosity study}

The changes in $\mathrm{pH}$ and dilution of feed that would occur in the gastrointestinal tract of chickens were simulated in vitro. The method used was adapted from that of CameronSmith et al. (1994) whereby $3 \mathrm{~g}$ of each of the diets was suspended in $15 \mathrm{ml}$ tap water at $40^{\circ}$ for $30 \mathrm{~min}$ in a $50 \mathrm{ml}$ test-tube. The samples were then centrifuged for $3 \mathrm{~min}$ at $1000 \mathrm{~g}$ after which a $3 \mathrm{ml}$ portion of the supernatant fraction was taken for measurement of viscosity on a Bohlin VOR Rheometer system (Bohlin Reologi, Science Park Ideon, Lund, Sweden) at a shear rate of $2.31 / \mathrm{s}$. Measuring temperature was $40^{\circ}$ and a cylindrical geometry system (C14) with a torque element of $1 \mathrm{gcm}$ was used. The tubes were then mixed using a vortex mixer and the suspensions acidified with $2.25 \mathrm{ml}$ of a $0.1 \mathrm{M}-\mathrm{HCl}$ and $54 \mathrm{mM}-\mathrm{NaCl}$ solution and incubated for $20 \mathrm{~min}$. After centrifugation measurement of supernatant fraction viscosity was made under the same conditions. The diets were then neutralized and diluted with $13 \mathrm{ml}$ of a solution containing $120 \mathrm{mM}-\mathrm{NaHCO}_{3}, 5 \mathrm{mM}-\mathrm{KCl}$ and $35 \mathrm{mM}-\mathrm{NaCl}$ and incubated for a further $20 \mathrm{~min}$. Measurements of viscosity were then made in the same way as previously described.

\section{Plasma lipid study}

On day 12 , chickens were starved for $8 \mathrm{~h}$ after which two birds from each cage (one of each sex), with weights as close as possible to the average group weight were slaughtered by cervical dislocation. Blood samples were collected from the jugular vein of each chicken for triacylglycerol and cholesterol analysis. 


\section{Digesta bile acids}

On day 13 of the experiment, two randomly selected birds from each of the four cages per diet were slaughtered by cervical dislocation. The gastrointestinal tracts of the chickens were quickly removed and the contents of the first third of the small intestine (denoted duodenum) were collected, pooled for each group (cage), frozen $\left(-25^{\circ}\right)$ and freeze-dried.

\section{Chemical analysis}

All analyses were carried out in duplicate and results are reported on a DM basis. Before analysis, representative feed samples were ground in a Tecator Cyclone Mill (Tecator AB, Höganäs, Sweden) to pass a $0.5 \mathrm{~mm}$ screen. Samples of freeze-dried digesta were ground in a Retsch mill $(0.5 \mathrm{~mm}$ screen size; Reitsch GmbH, Dusseldorf, Germany). DM was determined by oven drying at $105^{\circ}$ for $16 \mathrm{~h}$. Ash and crude protein $(\mathrm{N} \times 6.25)$ were analysed according to standard methods of the Association of Official Analytical Chemists (1984). Crude fat was extracted with petroleum ether in a Tecator Soxtec System HT after $3 \mathrm{M}-\mathrm{HCl}$ hydrolysis (Anon., 1971). Starch was determined enzymically (Åman \& Hesselman, 1984). Total dietary fibre, defined as the sum of NSP, enzyme-resistant starch and Klason lignin was analysed according to the method of Theander et al. (1995). Polyglucosamines derived from chitosan are, however, not derivatized to a component detected by the GLC procedures used and were therefore not analysed. Plasma was isolated from blood samples by centrifugation $(200 \mathrm{~g})$ and triacylglycerol, total cholesterol and HDL concentrations were analysed using enzymic colorimetric kits (Boehringer Mannheim Diagnostica, Mannheim, Germany).

Total content and composition of bile acids were measured by GLC after alkaline hydrolysis of freeze-dried samples with subsequent extraction of free acids according to the method of Bosaeus et al. (1986). The samples were then methyl esterified according to the method of Shaw \& Elliott (1978). The GLC analyses were performed on a Hewlett Packard 5890 instrument (Hewlett Packard, Avondale, PA, USA) fitted with an auto-injector and a DB-5 column $(30 \mathrm{~m} \times 0.25 \mathrm{~mm}$ i.d., He flow $1.5 \mathrm{ml} / \mathrm{min})$. The initial column temperature was $250^{\circ}$ which was increased to $265^{\circ}$ at a rate of $1 \% / \mathrm{min}$. Further heating of the column to $277^{\circ}$ was programmed at a rate of $2^{\circ} / \mathrm{min}$ and from $277^{\circ}$ to $310^{\circ}$ at a rate of $4 \% \mathrm{~min}$. The temperature was held at $310^{\circ}$ for $6 \mathrm{~min}$ and the total running time of the temperature programme was $35 \mathrm{~min}$. The GLC was calibrated with bile acid standards and the internal standards stigmasterol and 5- $\beta$-cholanic acid. Integration was performed using Gynkosoft (Gynkotech, Munich, Germany) software.

\section{Calculations and statistical analysis}

Statistical analysis of the registered variables (production results, plasma cholesterol, HDLcholesterol and triacylglycerol concentrations) was performed by an ANOVA procedure, the general linear model (GLM) supported by the statistical analysis system (Statistical Analysis Systems Institute Inc., 1985). In the statistical model, the main effects of diet (control, chitosan- or pectin-containing) and bird age were determined. The effect of sex was not taken into account when analysing production variables since these results are presented as cage means containing chickens of mixed sex. The effect of sex and the interaction between sex and diet were analysed by the GLM procedure for the plasma lipid study since these results were obtained from means for individual animals. Least significant differences derived from the $t$ test function of the SAS GLM procedure were used to make 
statistical comparisons. The pooled standard errors of the mean stated in the tables were obtained from the statistical analysis of cage means except for the plasma lipid study where these values were obtained from individual animals.

\section{RESULTS}

\section{Diets}

The starch contents of the chitosan and pectin broiler chicken diets were similar while the starch content of the control diet was approximately $18 \mathrm{~g} / \mathrm{kg}$ higher (Table 2). The chitosan diet had the highest crude protein content while the crude protein contents of the control and pectin diets were similar and lower. The total dietary fibre polysaccharide content was lower for the control and chitosan diets in comparison with the pectin diet. The similarity in the total dietary fibre polysaccharide content between the control and chitosan diets was due to the fact that $30 \mathrm{~g} / \mathrm{kg}$ of the chitosan was not analysed by the GLC procedure employed.

\section{Production study}

Mortality for the entire experiment was $3 \%$ and was not significantly affected by diet or bird age.

For the duration of the experiment broiler chicken live weights and feed intakes were significantly influenced $(P=0 \cdot 01)$ by diet and age while feed conversion ratio was significantly influenced by age only.

Feeding of the chitosan-containing diet significantly reduced body weight and cumulative feed intake in comparison with control-fed chickens (Table 3). Chitosan feeding generally elevated the feed conversion ratio in comparison with feeding the control and pectin diets.

\section{Viscosity study}

Diet viscosity was influenced by diet $(P=0.001)$ and treatment (suspension of diet in tap water, acidification and neutralization).

Following suspension of diets in tap water and the subsequent $30 \mathrm{~min}$ incubation, the supernatant-fraction viscosity of the control diet was numerically greater than that of the

Table 2. Chemical composition ( $\mathrm{g} / \mathrm{kg} \mathrm{DM})$ of the control, chitosan and pectin diets

\begin{tabular}{|c|c|c|c|}
\hline & \multicolumn{3}{|c|}{ Diets } \\
\hline & Control & Chitosan & Pectin \\
\hline Starch & 543.0 & $526 \cdot 1$ & $524 \cdot 5$ \\
\hline Crude protein & $180 \cdot 3$ & $201 \cdot 8$ & $185 \cdot 7$ \\
\hline Crude fat $(\mathrm{HCl})$ & 82.5 & $82 \cdot 3$ & $81 \cdot 5$ \\
\hline Ash & 78.2 & 78.7 & 78.5 \\
\hline \multicolumn{4}{|l|}{ Dietary fibre polysaccharide residues } \\
\hline Arabinose & $10 \cdot 8$ & $11 \cdot 2$ & 10.7 \\
\hline Xylose & $15 \cdot 5$ & $16 \cdot 3$ & $15 \cdot 4$ \\
\hline Glucose & $17 \cdot 1$ & $18 \cdot 7$ & $17 \cdot 0$ \\
\hline Uronic acids & $4 \cdot 6$ & 3.5 & $26 \cdot 3$ \\
\hline Total dietary fibre polysaccharide residues & 55.7 & 56.8 & $78 \cdot 3$ \\
\hline
\end{tabular}


Table 3. Live weight, cumulative feed intake and feed conversion ration of broiler chickens given control, chitosan or pectin diets*

(Mean values for four cages of birds per dietary group)

\begin{tabular}{|c|c|c|c|c|}
\hline & \multicolumn{3}{|c|}{ Diets } & \multirow[b]{2}{*}{ Pooled SEM $(\mathrm{df}=9)$} \\
\hline & Control & $\begin{array}{l}\text { Chitosan- } \\
\text { containing }\end{array}$ & $\begin{array}{c}\text { Pectin- } \\
\text { containing }\end{array}$ & \\
\hline \multicolumn{5}{|c|}{ Body wt (g) } \\
\hline Day 5 & $94^{\mathrm{a}}$ & $80^{b}$ & $94^{a}$ & 1.4 \\
\hline Day 11 & $168^{\mathrm{a}}$ & $132^{b}$ & $162^{\mathrm{a}}$ & 3.9 \\
\hline \multicolumn{5}{|c|}{ Cumulative feed intake $(\mathrm{g})$} \\
\hline Day 5 & $68^{\mathrm{a}}$ & $59^{\mathrm{b}}$ & $69^{a}$ & 1.8 \\
\hline Day 11 & $220^{\mathrm{a}}$ & $163^{\mathrm{b}}$ & $210^{\mathrm{a}}$ & $10 \cdot 1$ \\
\hline \multicolumn{5}{|c|}{$\begin{array}{l}\text { Feed conversion ratio } \\
\text { ( } \mathrm{g} \text { feed/g wt gain) }\end{array}$} \\
\hline Day 5 & $1 \cdot 30^{\mathrm{a}}$ & $1.53^{b}$ & $1 \cdot 34^{\mathrm{a}}$ & 0.04 \\
\hline Day 11 & $1.75^{\mathrm{a}}$ & $1.83^{\mathrm{a}}$ & $1.75^{\mathrm{a}}$ & 0.12 \\
\hline
\end{tabular}

a,b Mean values within a row not sharing a common superscript letter were significantly different $(P<0.05)$.

* For details of diets, see Tables 1 and 2 .

chitosan diet and significantly greater $(P<0.05)$ than that of the pectin diet (Table 4$)$. After acidification, however, supernatant-fraction viscosity of the chitosan diet increased to a level significantly greater than that of both the acidified control and pectin diets. Neutralization of the same samples reduced $(P<0.05)$ supernatant-fraction viscosity of the chitosan diet in comparison with the neutralized control and pectin diet samples.

\section{Plasma lipid study}

Total plasma cholesterol, plasma HDL-cholesterol and the plasma HDL-cholesterol:total cholesterol ratio were generally significantly influenced by diet, while plasma triacylglycerols generally were not significantly influenced by diet.

The chitosan significantly lowered the plasma total cholesterol concentration but elevated the HDL-cholesterol concentration in comparison with the pectin (Table 5). Consuming pectin had no effect compared with control-fed birds.

\section{Digesta bile acids}

Diet influenced the concentrations of chenodeoxycholic acid $(P=0.01)$ and total bile acids $(P=0.01)$ in the duodenal sections of the small intestine.

Table 4. Viscosity (m Pa.s) of the control, chitosan and pectin diets suspended in tap water, acidified $(\mathrm{HCl})$ and neutralized $\left(\mathrm{NaHCO}_{3}\right)^{*}$

(Mean values for ten determinations per diet)

\begin{tabular}{lcccc}
\hline \hline & \multicolumn{3}{c}{ Diets } & Pooled SEM (df 27) \\
\cline { 2 - 4 } & Control & Chitosan & Pectin & Pood \\
\hline Sample suspended in water, 30 min incubation & $621^{\mathrm{a}}$ & $503^{\mathrm{ab}}$ & $490^{\mathrm{b}}$ & $60 \cdot 2$ \\
Acidification 20 min incubation & $359^{\mathrm{a}}$ & $630^{\mathrm{b}}$ & $452^{\mathrm{a}}$ & 46.6 \\
Neutralization 20 min incubation & $323^{\mathrm{a}}$ & $143^{\mathrm{b}}$ & $326^{\mathrm{a}}$ & 26.4 \\
\hline \hline
\end{tabular}

a,b Mean values within a row not sharing a common superscript letter were significantly different $(P<0.05)$.

* For details of diets, see Tables 1 and 2. 
Table 5. Plasma triacylglycerol, total plasma cholesterol, plasma HDL-cholesterol and $H D L$ : total plasma cholesterol ratio (HDS : total) of broiler chickens given control, chitosan or pectin diets*

(Mean values for eight chickens per dietary group)

\begin{tabular}{llccr}
\hline \hline & \multicolumn{3}{c}{ Diets } & Pooled SEM (df 18) \\
\cline { 2 - 4 } & Control & Chitosan & Pectin & 0.05 \\
\hline Triacylglycerols $(\mathrm{mmol} / \mathrm{l})$ & $0.34^{\mathrm{a}}$ & $0.40^{\mathrm{a}}$ & $0.39^{\mathrm{a}}$ & 0.62 \\
Plasma cholesterol $(\mathrm{mmol} / \mathrm{l})$ & & & $7.32^{\mathrm{a}}$ & 0.17 \\
Total & $7.78^{\mathrm{a}}$ & $5 \cdot 60^{\mathrm{b}}$ & $3.08^{\mathrm{b}}$ & 0.04 \\
HDL & $2 \cdot 89^{\mathrm{ab}}$ & $2 \cdot 57^{\mathrm{a}}$ & $0.37^{\mathrm{a}}$ & \\
HDL : total & $0.37^{\mathrm{a}}$ & $0.51^{\mathrm{b}}$ & & \\
\hline \hline
\end{tabular}

${ }^{\mathrm{a}, \mathrm{b}}$ Mean values within a row not sharing a common superscript letter were significantly different $(P<0.05)$.

* For details of diets, see Tables 1 and 2 .

Table 6. Bile acid concentrations ( $\mathrm{mg} / \mathrm{g} \mathrm{DM}$ ) in the duodenum of broiler chickens given control, chitosan or pectin diets*

(Mean values for eight birds per dietary group)

\begin{tabular}{|c|c|c|c|c|}
\hline & \multicolumn{3}{|c|}{ Diets } & \multirow[b]{2}{*}{ Pooled SEM (df 22) } \\
\hline & Control & Chitosan & Pectin & \\
\hline \multicolumn{5}{|l|}{ Primary bile acids } \\
\hline Chenodeoxycholic acid & $34 \cdot 1^{\mathrm{a}}$ & $14 \cdot 9^{\mathrm{b}}$ & $21 \cdot 1^{\mathrm{b}}$ & 3.76 \\
\hline Cholic acid & $1.54^{\mathrm{a}}$ & $0.96^{\mathrm{a}}$ & $0.76^{\mathrm{a}}$ & 0.22 \\
\hline \multicolumn{5}{|l|}{ Secondary bile acid } \\
\hline Lithocholic acid & $0.06^{\mathrm{a}}$ & $0.04^{\mathrm{a}}$ & $4 \cdot 10^{\mathrm{a}}$ & $2 \cdot 19$ \\
\hline Total bile acids & $35 \cdot 7^{\mathrm{a}}$ & $15 \cdot 9^{\mathrm{b}}$ & $25 \cdot 0^{\mathrm{b}}$ & 3.70 \\
\hline
\end{tabular}

${ }^{\mathrm{a}, \mathrm{b}}$ Mean values within a row not sharing a common superscript letter were significantly different $(P<0.05)$.

* For details of diets, see Tables 1 and 2 .

Feeding of the chitosan and pectin diets reduced primary and total bile acid concentrations in the duodenum compared with control-fed animals (Table 6). Significant reductions $(P<0.05)$ in the concentrations of chenodeoxycholic and total bile acids among chickens given the fibre-containing (chitosan and pectin) diets relative to control-fed birds were observed.

\section{DISCUSSION}

Feeding of diets containing $30 \mathrm{~g}$ chitosan $/ \mathrm{kg}$ or up to $92 \mathrm{~g}$ sugarbeet fibre $/ \mathrm{kg}$ (containing pectin as a major dietary fibre component) has been shown to generally reduce body weights and feed intakes of broiler chickens (Pettersson \& Razdan, 1993; Razdan \& Pettersson, 1994). The explanation for this may be that gel-forming carbohydrates such as chitosan and pectin probably delay gastric emptying by increasing gastric viscosity (Sandhu et al. 1987). This in turn would increase satiety and reduce the capacity or the desire of the animal to consume more feed. The increased viscosity of the chitosancontaining diet when acidified, in the viscosity study of this experiment, infers a similar increase in viscosity in the acidic environment of the gizzard of chickens. The general lack of effect of feeding of the pectin diet on the production results when compared with 
animals receiving the control diet may, however, be attributed to the low viscosity of the pectin fraction or the fact that the inclusion level was probably too low for significant effects on these variables to be established.

Dietary fibres have been suggested to influence the absorption of cholesterol due to binding of dietary fibre to bile acids or to increased cholesterol turnover caused by fibreenhanced excretion of bile acids (Kritchevsky \& Story, 1993). Increased small-intestinal viscosity resulting in reduced uptake of dietary fat and resorption of bile acids is one possible mode of action of soluble dietary fibres (Cassidy \& Calvert, 1993).

Feeding of the chitosan or pectin diets generally reduced the concentrations of duodenal primary and total bile acids when compared with control-fed chickens in the present experiment, indicating an overall reduction in the production and secretion of primary bile acids by chickens given the fibre-containing diets. The reductions in primary and total bile acid concentrations observed in the present experiment would, at least for chickens receiving the chitosan diet, be expected, since losses of bile acids were probably enhanced. This was indicated by the reduced duodenal bile acid and total plasma cholesterol concentrations among chickens receiving the chitosan diet in comparison with animals given the control and pectin diets. It is noteworthy that a $30 \%$ reduction in total bile acid concentration was observed among chickens given the pectin diet in comparison with control-fed birds although only a minor concomitant decrease in the total plasma cholesterol concentration among these birds was observed. However, feeding of the chitosan diet reduced the total bile acid concentration by $55 \%$ in comparison with birds receiving the control diet and, in addition, reduced the total plasma cholesterol concentration significantly compared with both control- and pectin-fed birds. A possible explanation for these differences may be a better resorption of bile acids among birds receiving the pectin diet in comparison with those given the chitosan diet which is probable since pectin may only bind superficially to bile acids while chitosan may sequester bile acids more strongly. According to Oakenfull \& Sidhu (1984), the hypocholesterolaemic effect of pectin may not be related to binding of bile acids, but to increased gastrointestinal viscosity. In the present study, however, there was no evidence to suggest that pectin has a hypocholesterolaemic effect in broilers, which therefore precludes assumptions pertaining to the hypocholesterolaemic mechanism of pectin. Moreover, there was no statistically significant increase in viscosity of the pectin diet in comparison with the control diet at any stage of incubation in the in vitro experiment, perhaps reflecting similar conditions in the gastrointestinal tract of chickens fed with pectin. This would then support the lack of hypocholesterolaemic effects observed among chickens given the pectin diet since gastrointestinal viscosity was probably not elevated for chickens fed on this diet compared with control animals. In contrast, the significantly reduced viscosity of the chitosan diet after neutralization with bicarbonate in comparison with the other diets in the in vitro study may suggest a similar reduction in viscosity in the small intestine of broilers. Therefore, the hypocholesterolaemic effect of feeding of chitosan to chickens in the present experiment may be due to increased binding of bile acids by the polysaccharide but not inhibition of lipid uptake resulting from increased viscosity in the small intestine.

The results of the present experiment demonstrate the different hypolipidaemic potencies of chitosan and pectin in broiler chicken experiments. The hypolipidaemic effect of chitosan may be attributed to the reduction in duodenal bile acid concentration. The reduced viscosity of the chitosan diet at neutralization in the in vitro study may imitate a lower small-intestinal viscosity in vivo. Since the hypolipidaemic effect of dietary fibres is generally accepted to result from increased viscosity in the small intestine, it is unlikely that gastrointestinal viscosity was an important hypolipidaemic mechanism for chitosan in the present study. The level of pectin inclusion was probably too low for hypolipidaemic 
effects to be observed and consequently no conclusion can be drawn regarding the hypolipidaemic mechanism of pectin.

\section{REFERENCES}

Åman, P. \& Hesselman, K. (1984). Analysis of starch and other main constituents of cereal grains. Swedish Journal of Agricultural Research 14, 135-139.

Anderson, J. W. (1987). Dietary fiber, lipids and atherosclerosis. American Journal of Cardiology 60, 17G-22G. Anon. (1971). Determination of crude oils and fats. Official Journal of the European Communities L297, 995997.

Association of Official Analytical Chemists (1984). Official Methods of Analysis, 14th ed. Washington, DC: Association of Official Analytical Chemists.

Bosaeus, I., Carlsson, N. G. \& Andersson, H. (1986). Low-fat versus medium fat enteral diets. Scandinavian Joumal of Gastroenterology 21, 891-896.

Cameron-Smith, D., Collier, G. R. \& O'Dea, K. (1994). Effect of soluble dietary fibre on the viscosity of gastrointestinal contents and the acute glycaemic response in the rat. British Journal of Nutrition 71, 563-571.

Cassidy, M. M. \& Calvert, R. J. (1993). Effects of dietary fiber on intestinal absorption of lipids. In Dietary Fiber in Human Nutrition, pp. 153-162 [G. A. Spiller, editor]. Boca Raton: CRC Press.

Chang, M. L. W. \& Johnson, M. A. (1985). Effect of pectin, type of fat, and growing rate on lipid metabolism in rats. Nutrition Research 5, 749-757.

Deuchi, K., Kanauchi, O., Imasoto, Y. \& Kobayashi, E. (1994). Decreasing effect of chitosan on the apparent fat digestibility by rats fed on a high-fat diet. Bioscience, Biotechnology and Biochemistry 58, 1613-1616.

Furda, I. (1990). Interaction of dietary fiber with lipids - mechanistic theories and their limitations. In New Developments in Dietary Fiber, pp. 67-82 [I. Furda and C. J. Brine, editors]. New York: Plenum Press.

Ikeda, I., Sugano, M., Yoshida, K., Iwamoto, Y. \& Hatano, K. (1993). Effects of chitosan hydrolysates on lipid absorption and on serum and liver lipid concentrations in rats. Journal of Agricultural and Food Sciences 41, $431-435$.

Ikegami, S., Tsuchihashi, F., Harada, H., Tsuchihashi, N., Nishide, E. \& Innami, S. (1990). Effect of viscous indigestible polysaccharides on pancreatic-biliary secretion and digestive organs in rats. Journal of Nutrition 120, 353-360.

Kanauchi, O., Deuchi, K., Imasoto, Y. \& Kobayashi, E. (1994). Increasing effect of chitosan and ascorbic acid mixture on faecal dietary fat excretion. Bioscience, Biotechnology and Biochemistry 58, 1617-1620.

Kishimoto, Y., Wakabayashi, S. \& Takeda, H. (1995). Hypocholesterolemic effect of dietary fiber: relation to intestinal fermentation and bile acid excretion. Journal of Nutritional Science and Vitaminology 41, 151-161.

Kritchevsky, D. \& Story, J. A. (1993). Influence of dietary fiber on cholesterol metabolism in experimental animals. In Dietary Fiber in Human Nutrition, pp. 163-178 [G. A. Spiller, editor]. Boca Raton: CRC Press.

Maezaki, Y., Tsuki, K., Nakagawa, Y., Kawai, Y., Akimoto, M., Tsugita, T., Takekawa, W., Terada, A., Hara, H. \& Mitsuoka, T. (1993). Hypocholesterolemic effect of chitosan in adult males. Bioscience, Biotechnology and Biochemistry 57, 1439-1444.

Oakenfull, D. G. \& Sidhu, G. S. (1984). Effects of pectins on intestinal absorption of glucose and cholate in the rat. Nutrition Reports International 30, 1269-1278.

Pettersson, D. \& Aman, P. (1992). Production responses and serum lipid concentrations of broiler chickens fed diets based on oat bran and extracted oat bran with and without enzyme supplementation. Journal of the Science of Food and Agriculture 58, 569-576.

Petterson, D. \& Razdan, A. (1993). Effects of increasing levels of sugar-beet pulp in broiler chicken diets on nutrient digestion and serum lipids. British Journal of Nutrition 70,127-137.

Razdan, A. \& Pettersson, D. (1994). Effect of chitin and chitosan on nutrient digestibility and plasma lipid concentrations in broiler chickens. British Journal of Nutrition 72, 277-288.

Sandhu, K. S., El Samahi, M. M., Mena, I., Dooley, C. P. \& Valenzuela, J. E. (1987). Effect of pectin on gastric emptying and gastroduodenal motility in normal subjects. Gastroenterology 92, 486-492.

Shaw, R. \& Elliot, W. H. (1978). Bile acids. LV. 2,2 Dimethoxypropane: an esterifying agent preferred to diazomethane for chenodeoxycholic acid. Journal of Lipid Research 19, 783-787.

Statistical Analysis Systems Institute Inc. (1985). SAS User's Guide: Statistics. Cary, NC: SAS Institute Inc.

Theander, O., Aman, P., Westerlund, E., Andersson, R. \& Pettersson, D. (1995). Total dietary fiber determined as neutral sugar residues, and klason lignin (the Uppsala method): collaborative study. Journal of AOAC International 78, 1030-1044.

Trowell, H. (1972). Ischemic heart disease and dietary fiber. American Journal of Clinical Nutrition 25, 926930.

Welch, R. W., Peterson, D. M. \& Schramka, B. S. (1986). Hypocholesterolemic, gastrointestinal and associated responses to oat bran in chicks. Nutrition Research 6, 957-966. 